\title{
Gracilis muscle interposition with primary rectal without urethral repair for moderate sized rectourethral fistula caused by brachytherapy for prostate cancer: a case report
}

\author{
Narimantas Evaldas Samalavicius ${ }^{1 *}$, Raimundas Lunevicius ${ }^{2}$, Rakesh Kumar Gupta ${ }^{3}$, Tomas Poskus ${ }^{4}$
} and Albertas Ulys ${ }^{1}$

\begin{abstract}
Introduction: There is a $0.16 \%$ chance of a rectourethral fistula after prostate brachytherapy monotherapy using Palladium-103 or lodine-125 implants. We present an unusual case report of a rectourethral fistula following brachyradiotherapy monotherapy for prostate adenocarcinoma. It was also associated with unusual management of the fistula.

Case presentation: A 58-year-old Caucasian man underwent brachyradiotherapy monotherapy as definitive treatment for verified intracapsular prostate adenocarcinoma receiving 56 lodine-125 implants using a transrectal ultrasound-guided technique. The patient started to complain of severe perineal pain and mild rectal bleeding 15 months after brachyradiotherapy. A biopsy of mucosa of his anterior rectal wall was performed. A moderate sized rectourethral fistula was confirmed 23 months after implantation of lodine-125 seeds. Laparoscopic sigmoidostomy and suprapubic cystostomy were then performed. Long-term cortisone applications in combination with 30 sessions of hyperbaric oxygen therapy, and antibacterial therapies were initiated due to necrotic infection. A gracilis muscle interposition to create a partition between the patient's rectum and urethra in conjunction with primary rectal repair but without urethral repair were performed 6 months later. The $3 \mathrm{~cm}$ rectal defect was repaired via a $3 \mathrm{~cm}$-long horizontal perineal incision. The $1.5 \mathrm{~cm}$ urethral defect just below the prostate was not repaired. The patient underwent an optic internal urethrotomy 3 months later for a $1.5 \mathrm{~cm}$-long urethral stricture. Several planned preventive urethral buginages were performed to avoid urethral stricture recurrence. At 12 months postoperatively, there were no signs of a fistula and cancer recurrence. He now has a normal voiding and anal continence.

Conclusion: Severe rectal pain, bleeding, and local anterior necrotic proctitis are predictors of a rectourethral fistula. Urinary and fecal diversion is the first-step operation. Gracilis muscle interposition in conjunction with primary rectal repair but without urethral reconstruction is one of the reconstructive surgery options for moderate $2 \mathrm{~cm}$ to $3 \mathrm{~cm}$ rectourethral fistulas. Internal urethrotomy is a procedure for postoperative urethral strictures of $1.5 \mathrm{~cm}$ in length.
\end{abstract} Keywords: Brachytherapy, Gracilis interposition, Prostate cancer, Radiotherapy, Rectal repair, Rectourethral fistula

\footnotetext{
* Correspondence: narimantas.samalavicius@vuoi.lt

${ }^{1}$ Faculty of Medicine, Vilnius University, Oncology Institute, 1 Santariskiu

Street, Vilnius, LT 08406, Lithuania

Full list of author information is available at the end of the article
} 


\section{Introduction}

There is a $0.16 \%$ chance of a rectourethral fistula (RUF) after prostate brachytherapy (BT) monotherapy using Palladium-103 or Iodine-125 implants [1]. However, if RUFs occur as sequelae of $\mathrm{BT}$, it is more complex comparing with RUF following radical prostate surgery thus creating a more burdensome reconstructive effort $[2,3]$. Interestingly, theoretical background regarding management of RUFs following BT for prostate carcinoma is limited, yet an online search of the PubMed database using the filter 'Rectourethral fistula and brachytherapy' revealed only 10 references. We present an unusual case report of a RUF following brachyradiotherapy monotherapy for histologically verified stage I prostate adenocarcinoma that was successfully managed by complex therapy including gracilis muscle interposition surgery with primary rectal but without urethral repair.

\section{Case presentation}

A 58-year-old Caucasian man underwent BT monotherapy as definitive treatment for verified intracapsular prostate adenocarcinoma receiving 56 Iodine- 125 implants using a transrectal ultrasound-guided technique. The initial serum prostate-specific antigen level fell from 3.5 to $0.002 \mathrm{ng} / \mathrm{mL}$. The patient started to complain of severe perineal pain and mild rectal bleeding 15 months after BT. A biopsy of mucosa of the patient's anterior rectal wall revealed inflammatory changes above the dentate line and cortisone was continuously applied locally. This therapy was stopped 8 months later when fecaluria, urine leakage per rectum, pelvic pain, orchiepididymitis, and fever were documented. Laparoscopic sigmoidostomy and suprapubic cystostomy were then performed. The patient was referred to a tertiary oncology center because of increasing pain 2 months after this procedure. An extensive necrotic perifistulous injury was obvious. Thus long-term cortisone applications in combination with 30 sessions of hyperbaric oxygen therapy (HBOT), and antibacterial therapies were initiated. After 6 months (Figure 1), when clinical resolution of necrotic perifistulous infection was confirmed and distal urinary obstruction was ruled out, a gracilis muscle interposition to create a partition between the patient's rectum and urethra in conjunction with primary rectal but without urethral repair was performed. The $3 \mathrm{~cm}$ rectal defect was repaired via a $3 \mathrm{~cm}$-long horizontal perineal incision with interrupted single layer vicryl sutures. The $1.5 \mathrm{~cm}$ urethral defect just below the prostate was not repaired. The tendon of the right gracilis muscle was fixed to the left pubic bone. Vicryl was applied to fix the gracilis to the rectal wall and tissues lying around the urethra. Before skin closure, a small suction drain was then placed in the perineal wound. Full healing of

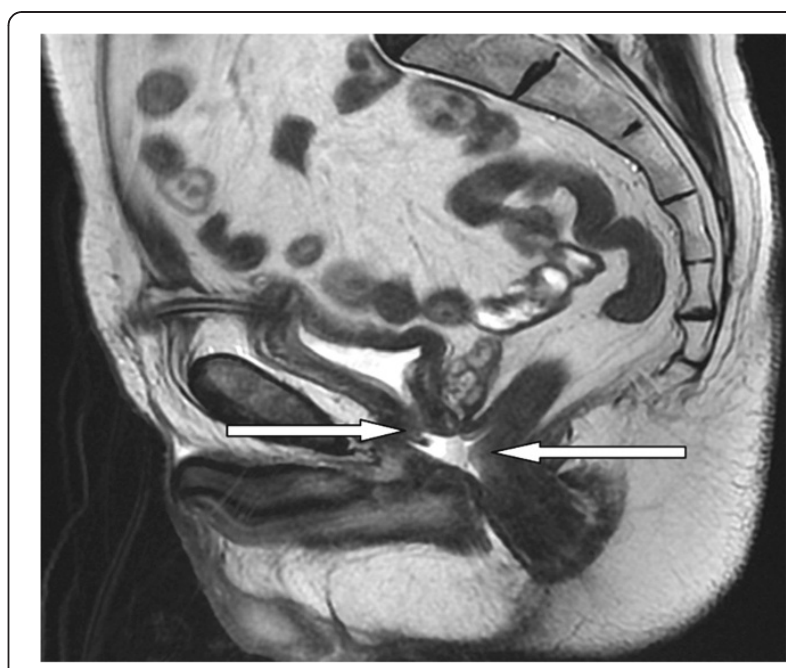

Figure 1 Magnetic resonance image demonstrating moderate sized rectourethral fistula (arrows).

the rectal wall was later confirmed 2 months after reconstructive surgery (Figure 2). Sigmoidostomy takedown operation was performed after 8 weeks; the patient underwent an optic internal urethrotomy 3 months later for a $1.5 \mathrm{~cm}$-long urethral stricture. The suprapubic cystostomy catheter was removed. A urinary catheter was inserted via the external urethral meatus, and was left in the bladder for 3 weeks. Several planned preventive urethral buginages were performed to avoid urethral stricture recurrence. At 12 months postoperatively, there were no signs of a fistula or cancer recurrence. He now has a normal voiding and anal continence.

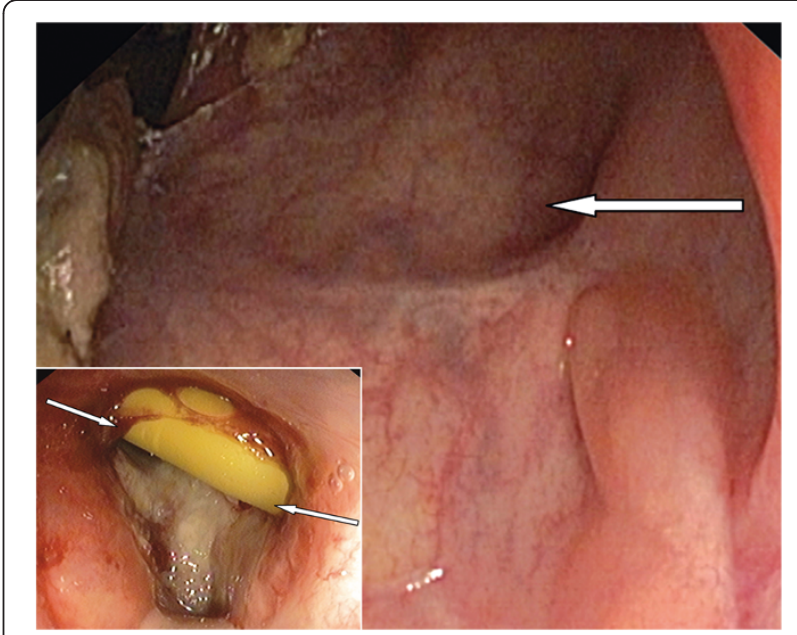

Figure 2 Site of rectourethral fistula (arrow) 2 months after transverse repair of the rectum and gracilis interposition procedure; at the lower left corner, rectourethral fistula 2 months before reconstructive surgery (arrows indicate Foley catheter). 


\section{Discussion}

In the light of previously described post-radiotherapy RUF size with a mean of $2.8 \mathrm{~cm}$ [4] and average diameter of $3.2 \mathrm{~cm}$ [5], the RUF presented in our paper should be described as moderate sized. It is said that patients with a fistula that is greater than $1 \mathrm{~cm}$ in diameter should undergo gracilis interposition in conjunction with primary rectal repair and buccal mucosa grafting urethral reconstruction [4]. However, the issue of RUF classification and patients' stratification remains open in this clinical setting.

The fistula described is a late sequela of BT. Severe perineal pain, mild bleeding, and local proctitis were predisposing factors. These RUF predictors should be taken into consideration responsibly because a longterm patient's surveillance plan can be established for timely diagnosis of RUF because it can occur a few years after Iodine-125 seed implantation [5]. Furthermore, because an anterior rectal biopsy after prostate radiation has been associated with a higher incidence of RUF formation, an anterior rectal biopsy should not be performed unless there is an obvious cancer staging-related indication for a biopsy. RUF formation after BT is reported to be up to $8.8 \%$ if an anterior rectal biopsy is taken after this radiotherapy procedure [1,2].

Long-term local use of cortisone for a conservative treatment of proctitis which is associated with BT is controversial. There are no reports supporting such conservative management of post-BT proctitis. Retrospectively, we assume that long-term steroid therapy for proctitis was a risk factor for RUF. We also postulated that HBOT may result in accelerated healing of injured tissues because it is thought that HBOT improves oxygen supply to wounds and therefore improves their healing. Again, there is no evidence supporting the HBOT in the management of patients with radiation-induced pelvic soft tissue necrosis including proctitis [6].

As there is no standardized treatment for a BT-induced RUF the responsibility for treatment is borne by the physicians in charge. Our chosen surgical strategy resulted in a good outcome and it was similar to an earlier proposed procedure [4]. Nevertheless, the case report highlights one significant difference: there was no attempt to perform substitution urethroplasty either way, by primary repair or buccal mucosa reconstruction [7]. Moreover, postoperative formation of a membranous urethral stricture up to $1.5 \mathrm{~cm}$ was predicted before and during the reconstructive surgery. Optic internal urethrotomy was a further treatment option because the urethral stricture was $1.5 \mathrm{~cm}$ in length. Timely gracilis muscle transposition and rectal repair were key elements of successful RUF treatment. Although it is believed that radiotherapyinduced RUFs are much more challenging to reconstruct than inflammatory, iatrogenic, and traumatic RUFs because the magnitude of fibrotic tissue in the area of RUF is extensive [4], it is not the case for every patient. Duration from insertion of radioactive implants to reconstructive surgery is possibly the main factor for the magnitude of fibrotic tissue around the RUF. Finally, in terms of good quality of life, it is believed that transperineal repair with gracilis muscle interposition is an effective treatment for patients with complex RUFs following radiotherapy. However, long-term follow-up studies are needed.

\section{Conclusion}

Prostate adenocarcinoma BT monotherapy may lead to significant RUF-related long-term morbidity. Severe perineal pain, rectal bleeding, and local anterior proctitis are predictors of RUFs. Urinary and fecal diversion is the first-step operation in management of RUFs. Gracilis muscle interposition in conjunction with primary rectal but without urethral reconstruction is one of the reconstructive surgery options for a moderate sized RUF. Internal urethrotomy is a procedure for postoperative urethral stricture $1.5 \mathrm{~cm}$ in length.

\section{Consent}

Written informed consent was obtained from the patient for publication of this case report and any accompanying images. A copy of the written consent is available for review by the Editor-in-Chief of this journal.

\section{Competing interests}

The authors declare that they have no competing interests.

\section{Authors' contributions}

All authors equally participated in the design of the paper. RKG carried out provisional drafting. TP helped to write a provisional draft. RL performed systematic and final literature search, review, interpretation of literature data, secondary and final drafting. NES carried out the critical revision of the manuscript and participated in presentation of the medical case report. AU acted as a urology consultant. All authors read and approved the final manuscript.

\section{Author details}

${ }^{1}$ Faculty of Medicine, Vilnius University, Oncology Institute, 1 Santariskiu Street, Vilnius, LT 08406, Lithuania. King's College Hospital NHS Foundation Trust, King's Health Partners Academic Health Sciences Centre, Denmark Hill, London, SE5 9RS, UK. ${ }^{3}$ Department of Surgery, B.P. Koirala Institute of Health Sciences, Dharan, Nepal. ${ }^{4}$ Vilnius University Hospital Santariskiu Klinikos

Center Branch, 3 Zygimantu Street, Vilnius LT 01128, Lithuania.

Received: 10 May 2012 Accepted: 16 August 2012

Published: 25 September 2012

\section{References}

1. Theodorescu D, Gillenwater JY, Koutrouvelis PG: Prostatourethral-rectal fistula after prostate brachytherapy. Cancer 2000, 89:2085-2091.

2. Zinman L: The management of the complex recto-urethral fistula. BJU Int 2004, 94:1212-1213.

3. Zmora O, Potenti FM, Wexner SD, Pikarsky AJ, Efron JE, Nogueras JJ, Pricolo VE, Weiss EG: Gracilis muscle transposition for iatrogenic rectourethral fistula. Ann Surg 2003, 237:483-487. 
4. Lane BR, Stein DE, Remzi FH, Strong SA, Fazio WW, Angermeier KW: Management of radiotherapy induced rectourethral fistula. J Urol 2006, 175:1382-1387. Morrey A. Editorial comment, 1387-8.

5. Chrouser KL, Leibovich BC, Sweat SD, Larson DW, Davis BJ, Tran NV, Zincke $H$, Blute ML: Urinary fistulas following external radiation or permanent brachytherapy for the treatment of prostate cancer. J Urol 2005, 173:1953-1957.

6. Bennett MH, Feldmeier J, Hampson N, Smee R, Milross C: Hyperbaric oxygen therapy for late radiation tissue injury. Cochrane Database Syst Rev 2005, 20:CD005005.

7. Elliott SP, McAninch JW, Chi T, Doyle SM, Master VA: Management of severe urethral complications of prostate cancer therapy. J Urol 2006, 176(6 Pt 1):2508-2513.

doi:10.1186/1752-1947-6-323

Cite this article as: Samalavicius et al:: Gracilis muscle interposition with primary rectal without urethral repair for moderate sized rectourethral fistula caused by brachytherapy for prostate cancer: a case report. Journal of Medical Case Reports 2012 6:323.

\section{Submit your next manuscript to BioMed Central and take full advantage of:}

- Convenient online submission

- Thorough peer review

- No space constraints or color figure charges

- Immediate publication on acceptance

- Inclusion in PubMed, CAS, Scopus and Google Scholar

- Research which is freely available for redistribution 